\title{
Studies on the Shielding Properties of Transparent Glasses Prepared from Rice Husk Silica
}

\author{
A. G. Mostafa ${ }^{1}$, H. A. Saudi ${ }^{2}$, M. Y. Hassaan ${ }^{1}$, S. M. Salem ${ }^{1}$, S. S. Mohammad \\ ${ }^{1}$ Department of Physics, Faculty of Science, Al-Azhar University, Nasr City, Egypt \\ ${ }^{2}$ Department of Physics, Faculty of Science (Girls' Branch), Al-Azhar University, Nasr City, Egypt
}

Email address:

Saied_saber2008@yahoo.com(S. S. Mohammad)

\section{To cite this article:}

A. G. Mostafa, H. A. Saudi, M. Y. Hassaan, S. M. Salem, S. S. Mohammad. Studies on the Shielding Properties of Transparent Glasses Prepared from Rice Husk Silica. American Journal of Modern Physics. Vol. 4, No. 4, 2015, pp. 149-157. doi: 10.11648/j.ajmp.20150404.11

\begin{abstract}
The glasses studied here have been prepared by the melt quenching technique from Egyptian rice husk silica.The obtained solid glasses exhibit amorphous nature and transparency. These glasses were selected to obey the following composition, (75-x) mol \% RH silica. $25 \mathrm{~mol}_{\%} \mathrm{Na}_{2} \mathrm{O} . \mathrm{x} \mathrm{mol} \% \mathrm{Bi}_{2} \mathrm{O}_{3}$, where $\mathrm{x}$ takes the values, $0,5,10,15$ and 20 . It was found that, as $\mathrm{Bi}_{2} \mathrm{O}_{3}$ was gradually increased both the density and molar volume values increased. The comparison between the experimental and empirical density and molar volume values confirm that all the studied glasses are in amorphous glassy phase. Moreover, all samples showed also good shielding properties against gamma ray radiation and neutrons. The mass attenuation coefficient of gamma ray radiation increased gradually as $\mathrm{Bi}_{2} \mathrm{O}_{3}$ was gradually increased while the HVL values exhibit gradual decrease, and the sample that contains $20 \mathrm{~mol} \% \mathrm{Bi}_{2} \mathrm{O}_{3}$ appeared the efficient one at low gamma ray energy (especially at 356 $\mathrm{KeV}$ ). On the other hand "for shielding neutrons" the sample that contains $5 \mathrm{~mol} \% \mathrm{Bi}_{2} \mathrm{O}_{3}$ appeared the best one since it exhibits the highest neutron removal cross section.
\end{abstract}

Keywords: Bismuth Oxide, Agricultural Wastes, Egyptian RH- Silica, Shielding Properties, Radioactive Sources, Fast Neutron

\section{Introduction}

It is worth mentioning that, radioactive sources are not dangerous to human bodies only but they are also detrimental to all sensitive laboratory equipments. Therefore, shielding is necessary to protect mankind and all equipments from penetrative neutrons and gamma-ray energies. It was known that the intensity of gamma-ray varies according to three factors: time, distance and shielding, but the most effective method to attenuate radiation is shielding [1]. Chanthima et al, $[2,3]$ studied the photon interactions and shielding properties of silicate glasses containing $\mathrm{Bi}_{2} \mathrm{O}_{3}, \mathrm{BaO}$ and $\mathrm{PbO}$. Their results showed that silicate glass containing $\mathrm{Bi}_{2} \mathrm{O}_{3}$ exhibits the best shielding properties followed by those containing $\mathrm{PbO}$ and $\mathrm{BaO}$, respectively, and in all cases, glasses are better than concrete. Kaewkhao and Limsuwan [4] showed that, glasses containing heavy-metal oxide such as $\mathrm{Bi}_{2} \mathrm{O}_{3}$ are promising gamma-ray shielding materials due to their high effective atomic number and strong absorption coefficient of gamma ray. Kirdsiri et al [5] studied gamma-ray shielding and optical properties of borate and silicate glasses containing $\mathrm{Bi}_{2} \mathrm{O}_{3}, \mathrm{PbO}$ and $\mathrm{BaO}$ at $662 \mathrm{keV}$. They found that increasing the additive of the heavy metal oxide, the photoelectric absorption increased while Compton scattering decreased. Kurudirek et al [6] reported a comparative study of the effective atomic number for several glasses containing $\mathrm{Pb}$ to lead free systems. They observed that at high energy regions, the lead free glasses showed higher values of effective atomic numbers than lead based glasses. Manohara et al [7] studied the effective atomic numbers and related parameters for $\mathrm{CaO}$ $\mathrm{SrO}-\mathrm{B}_{2} \mathrm{O}_{3}, \mathrm{PbO}-\mathrm{B}_{2} \mathrm{O}_{3}, \mathrm{Bi}_{2} \mathrm{O}_{3}-\mathrm{B}_{2} \mathrm{O}_{3}$, and $\mathrm{PbO}-\mathrm{Bi}_{2} \mathrm{O}_{3}-$ $\mathrm{B}_{2} \mathrm{O}_{3}$ glasses at photon energy ranges from $1 \mathrm{keV}$ to $1 \mathrm{GeV}$. They found that for medium- $Z$ glasses, effective atomic number was nearly constant and equal to the mean atomic number in a wide energy range dominated by Compton scattering process. Singh et al [8-12] has found a good agreement between the experimental and theoretical (calculated by the WinXCom program) values of gamma-ray mass attenuation coefficient, the Photon mean free path (MFP), the effective atomic number and the effective electron density 
for $\mathrm{ZnO}-\mathrm{PbO}-\mathrm{B}_{2} \mathrm{O}_{3}$ glasses, investigated at photon energies of $511,662,1173$ and $1332 \mathrm{keV}$. Singh et al $[13,14]$ carried out two respective studies on the radiation shielding properties of lead barium borate glass and bismuth lead borate glasses. They found that the half value layer decreased with increasing the weight fraction of $\mathrm{Pb}$ and $\mathrm{Bi}$. Gerward et al $[15,16]$ studied gamma ray interaction with barium - borate - (fly ash) rice husk $(\mathrm{RH})$ silica glasses by measuring the attenuation coefficient in the photon energy range of $356-1332 \mathrm{keV}$. They observed also good agreement between the radiation parameters obtained experimentally and theoretically.

From another point of view, Rice husk (RH) is an agricultural residue abundantly available in rice producing countries. In Egypt, a rice husk is one of the major agricultural wastes. Much of this by-product is either burnt or dumped as waste, since limited proportion has been recycled as a raw material for cement industry. But the excessive addition of RH silica to cement act to deteriorate its quality. Furthermore, the demand of cement tends to fluctuate with the construction industry while RH generation increases gradually [17].

Therefore, it is necessary to search for new options to recycle $\mathrm{RH}$. One possibility is to use $\mathrm{RH}$ in glass manufacturing, because of the high silica content and low transition oxide contamination. Therefore, many researches have been carried out to extract pure amorphous silica from RH [18-20].

However, in this article, a trial will be done to prepare some bismuth sodium silicate glasses, where $\mathrm{SiO}_{2}$ was extracted from RH. The preparation of these glasses aims to produce low cost, good transparent and effective shielding materials for the harmful ray.

\section{Experimental Procedure}

Detailed information about the method used to extract silica from RH was found in ref. [20]

An appropriate amount of sodium carbonate, bismuth oxide and RH silica were weighed using an electric balance having accuracy of $0.0001 \mathrm{~g}$. The batches were mixed well and were then melted in porcelain crucibles at $1300{ }^{\circ} \mathrm{C}$ for $2 \mathrm{~h}$ using an electric muffle furnace. The melts were stirred several times during melting in order to supply homogeneous glasses having the composition (75-x) mol\% RH-silica. $\mathrm{x} \mathrm{mol} \% \mathrm{Bi}_{2} \mathrm{O}_{3} .25$ $\operatorname{mol} \% \mathrm{Na}_{2} \mathrm{O}$, (where $0 \leq \mathrm{x} \leq 20$ ). The melts were quenched in air between two cupper plates, and just after sitting the solid glasses were directly transferred to the annealing furnace at $350{ }^{\circ} \mathrm{C}$ and the furnace was turned off and was left to cool to room temperature over-night [21]. All samples appeared transparent and exhibit pure amorphous nature.

The densities of the studied glasses were measured applying Archimedes technique, using $\mathrm{CCl}_{4}$ as an immersing liquid of stable density $=1.593 \mathrm{gm} / \mathrm{cm}^{3}$ at RT. The experimental density
( $\rho$ exp ) can be calculated applying equation (1),

$$
\rho_{\exp }=\frac{M_{a}}{M_{a}-M c} \rho_{c}
$$

Where: $\mathrm{M}_{\mathrm{a}}$ and $M c$ are the masses of the sample in air and $\mathrm{CCl}_{4}$ respectively and $\rho_{c}$ is the density of $\mathrm{CCl}_{4}$.

The empirical densities ( $\rho_{\mathrm{emp}}$ ) were also calculated applying equation (2) and were exhibited in the same figure for comparison.

$$
\rho_{\text {emp }}=\sum_{j} \rho_{j} \cdot p_{j}
$$

Where $\rho_{1}, \rho_{2}, \rho_{3}, \ldots \rho_{\mathrm{j}}$ are the densities of the constituting oxides and $\mathrm{P}_{1}, \mathrm{P}_{2}, \mathrm{P}_{3}, \ldots \ldots \ldots . ., \mathrm{P}_{\mathrm{j}}$ are the percentage weight of each oxide composing such sample.

It is of interest to calculate the molar volume values, since it relates directly to the internal spatial structure of materials. However, both the experimental and the empirical molar volume values were calculated using equations (3 and 4) respectively,

$$
\begin{aligned}
& \left(\mathrm{V}_{\mathrm{m}}\right)_{\exp }=\Sigma\left(\mathrm{M}_{\mathrm{i}} / \rho_{\mathrm{exp}}\right) \\
& \left(\mathrm{V}_{\mathrm{m}}\right)_{\mathrm{emp}}=\Sigma\left(\mathrm{M}_{\mathrm{i}} / \rho_{\mathrm{emp}}\right)
\end{aligned}
$$

Mass attenuation coefficient has been determined empirically by using WIN XCOM computer software developed by NIST [22-27].

The values of the total mass attenuation coefficients of the studied glasses were calculated by Win X-COM program, based on the mixture rule (equation (5)),

$$
\left(\frac{\mu}{\rho}\right)_{\mathrm{m}}=\sum_{\mathrm{i}=0}^{\mathrm{n}} \mathrm{w}_{\mathrm{i}}\left(\frac{\mu}{\rho}\right)_{\mathrm{m}(\mathrm{i})}
$$

Where $(\mu / \rho)_{m}$ is the total mass attenuation coefficient for a glass sample and $\mathrm{w}_{\mathrm{i}}$ is the fractional weight of each oxide in such sample.

The half value layers (HVL) of the studied glass were also calculated according to the equation:

$$
\mathrm{HVL}=\ln 2 / \mu
$$

Where $\mu$ is the linear attenuation coefficient.

\section{Results and Discussion}

The chemical composition of RH after chemical and

\begin{tabular}{|c|c|c|c|c|c|c|}
\hline Constituents (Weight \%) & $\mathrm{SiO}_{2}$ & $\mathbf{K}_{2} \mathbf{O}$ & $\mathrm{CaO}$ & $\mathrm{Fe}_{2} \mathrm{O}_{3}$ & $\mathrm{MnO}_{2}$ & $\mathrm{TiO}_{2}$ \\
\hline Slow heating at $750{ }^{\circ} \mathrm{C} \mathrm{RH}$ SILICA & 98.6 & 0.23 & 0.688 & 0.28 & 0.042 & 0.08 \\
\hline
\end{tabular}
thermal treatments is presented in Table (1). It was seen that the extracted silica reached $98.6 \%$ of $\mathrm{RH}$, in addition to slight traces composed mainly of potassium, calcium, iron and other ignored oxides.

Table 1. Impurity analysis in wt. \% and Major chemical constituents of Egyptian rice husk fly ash after treatment. 


\subsection{Density ( $\rho)$ and Molar Volume $\left(V_{m}\right)$}

Density is an important and accurate property, which strongly reflect the fine changes in the glass structure. Therefore the obtained experimental density values of the studied glasses were plotted as a function of $\mathrm{Bi}_{2} \mathrm{O}_{3}$ content in Fig. 1, the change in the empirical density was also depicted in the same figure, for comparison.

As was expected, both the experimental and empirical densities increased gradually as $\mathrm{Bi}_{2} \mathrm{O}_{3}$ was gradually increased. It is obvious that the empirical density values are usually higher than those obtained experimentally. The rate of the increase of the empirical density was found to be $0.15 \mathrm{~g} / \mathrm{cm}^{3}$ per mol which was found to be higher than the calculated slop of the experimental one that was found to be $0.09 \mathrm{~g} / \mathrm{cm}^{3}$ per mol. All these factors can be taken as evidence for the homogeneity of the glassy state of the prepared samples [28].

The gradual increase in the density values can be attributed to the replacement of one mole of $\mathrm{RH}$ silica (mean molecular weight $=60.08 \mathrm{~g} / \mathrm{mol}$ ) by one mole of $\mathrm{Bi}_{2} \mathrm{O}_{3}$ (molecular weight $=465.96 \mathrm{~g} / \mathrm{mol})$.

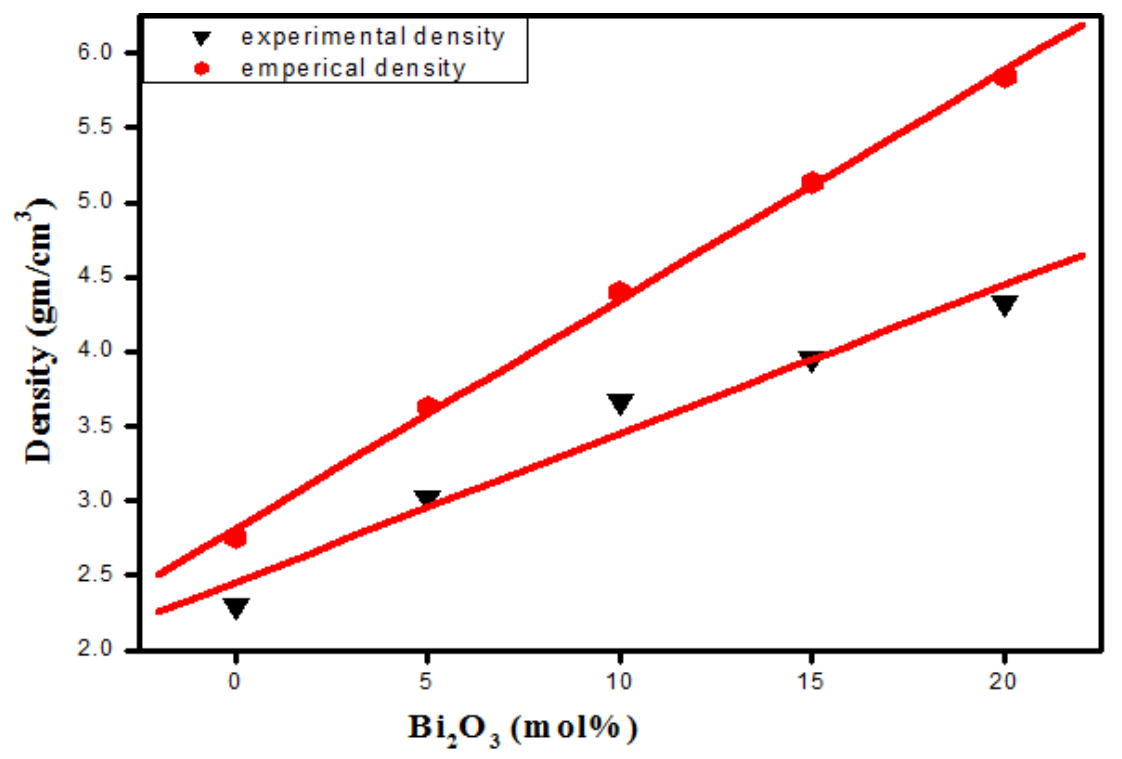

Fig. 1. The change in the experimental and empirical densities versus $\mathrm{Bi}_{2} \mathrm{O}_{3}$ content.

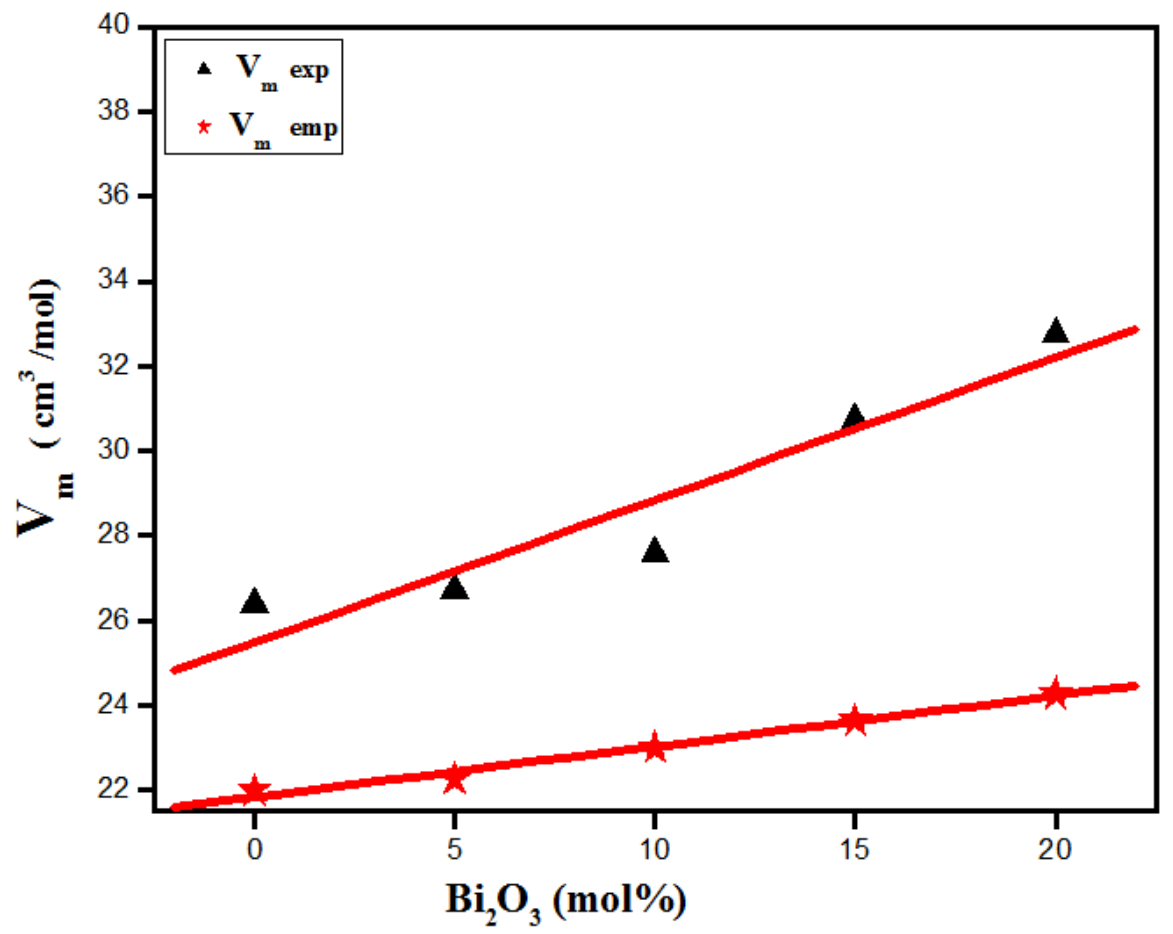

Fig. 2. The change of the experimental and empirical molar volume versus $\mathrm{Bi}_{2} \mathrm{O}_{3}$ content. 
The molar volume, which is defined as the volume occupied by one mole of the material, increases from 27.38 to $32.77 \mathrm{~cm}^{3}$ $\mathrm{mol}^{-1}$ as $\mathrm{Bi}_{2} \mathrm{O}_{3}$ content raises from 0 to 20 mol.\%. Shelby [29] reported that the molar volume depends on the ionic radius of the modifier cations. If the ionic radius of the modifier ions (ionic radius of $\mathrm{Bi}^{3+}$ is $1.03 \mathrm{~A}^{\circ}$ ) is larger than the interstices of the network structure (ionic radius of $\mathrm{Si}^{4+}$ is $0.40 \mathrm{~A}^{\circ}$ ) their attraction to the oxygen ions can lead to an augment in the size of the interstices and this enhance the molar volume. Therefore Fig. (2), shows the gradual change in the molar volume of the studied glasses versus bismuth oxide content. The empirical molar volume was also represented in the same figure for comparison. A gradual increase was clearly observed in both values of the empirical and the experimental $\mathrm{V}_{\mathrm{m}}$.

It is obvious from this figure that the rate of increase of the experimental $\mathrm{V}_{\mathrm{m}}$ is higher than that of the empirical one, which can be taken also as evidence that the prepared samples are of highly homogeneous glassy phase [28].

The observed increase of $\mathrm{V}_{\mathrm{m}}$ can be also attributed to:
1. The replacement of one $\mathrm{Si}$ cation (ionic radii $\mathrm{R}_{\mathrm{i}}=0.4 \mathrm{~A}^{\circ}$ by two $\mathrm{Bi}$ cations (ionic radii of each, $\mathrm{R}_{\mathrm{i}}=1.03 \mathrm{~A}^{\circ}$ ).

2. The oxygen anions concentration in the glass networks is gradually increased, since two oxygen anion $\left(\mathrm{SiO}_{2}\right)$ were replaced by three oxygen anions $\left(\mathrm{Bi}_{2} \mathrm{O}_{3}\right)$. This can be confirmed by calculating the number of oxygen ion density in the studied glasses, using the following equation,

$$
\mathrm{N}_{0-\text { ions }}=\sum_{\mathrm{i}} \mathrm{x}\left[\left(\rho \frac{\mathrm{Wti}}{\mathrm{MWi}}\right) \mathrm{NA}\right]
$$

Where $\rho$ is the experimental density \& $\mathrm{W}_{\mathrm{t}}$ is the percentage weight of each component, $\mathrm{M}_{\mathrm{W}}$ is the molecular weight of each molecule, $\mathrm{N}_{\mathrm{A}}$ is Avogadro's number and $\mathrm{x}$ is the number of oxygen atoms in each molecule.

Fig. 3 shows that the number of oxygen ion density increased gradually as bismuth oxide was gradually increased. This result confirms the gradual extension of the oxygen network, which in turn act to increase the molar volume.

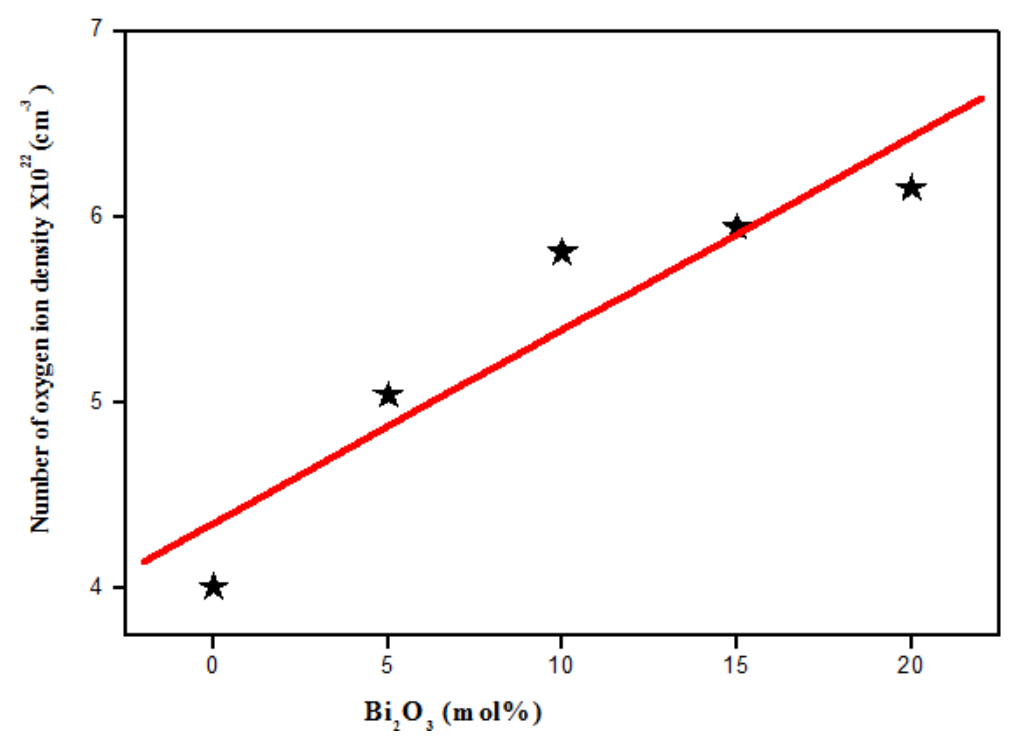

Fig. 3. The gradual change in the number of oxygen ion density versus $\mathrm{Bi}_{2} \mathrm{O}_{3}$ content.

The result of these glass samples agree well with those reported elsewhere [29-33].

Qi et al [34] have relates the density of binary silicate, borate and phosphate glasses including $\mathrm{Bi}_{2} \mathrm{O}_{3}$ to the electronic polarizability of the oxide ions and therefore the data are larger than those of binary oxide glasses containing monovalent or divalent metals (by one or two order of magnitude).

It was found that the density and molar volume increased progressively with gradual increase of $\mathrm{Bi}_{2} \mathrm{O}_{3}$. This is a similar behavior to the data obtained in ref. [35]

\subsection{Gamma - Ray Attenuation Properties}

\subsubsection{Total Mass Attenuation Coefficient and Half Value Layer as a Function of Bismuth Oxide Content}

Nowadays, owing to the universal uses of many types of radio-active sources in different fields (medicine, industry, agriculture ... etc.), daily life becomes dangerous especially for users, since they have to be in contact to different harmful ray. However, the search for suitable shielding materials becomes now of interest. On this sense, the prepared glasses were checked whether they can be used as transparent shield or not.

The $\gamma$-ray mass attenuation coefficients $\left[(\mu / \rho)_{\mathrm{m})}\right]$ have been calculated using Win X-COM program,

1. Firstly at different low $\gamma$-ray energies $(356,663,1173$ and $1332 \mathrm{KeV}$, emitted from ${ }^{133} \mathrm{Ba},{ }^{137} \mathrm{Cs}$ and ${ }^{60} \mathrm{Co}$ (for both 1173 and 1332) respectively [35]. Fig. (4) Shows the change in the $\gamma$-ray mass attenuation coefficient with the gradual increase of bismuth oxide where a gradual increase of $(\mu / \rho)_{m}$, can be easily observed.

2. Secondly, Fig. (5) Shows the change in the mass 
attenuation coefficient of the studied glasses at high $\gamma$-ray energies (10 up to $100 \mathrm{MeV}$ ). It appeared that as bismuth oxide was gradually increased, the mass attenuation coefficient increased also.

3. The HVL of the studied glasses was also calculated for the same $\gamma$-ray energies considered above. The obtained values as a function of bismuth oxide are represented in Figs ( $6 \& 7$ ) for low and high energies $\gamma$-ray respectively. It can be seen obviously that the HVL decreased gradually with the gradual increase of bismuth oxide content.

The observed increase in the $\gamma$-ray mass attenuation coefficient as well as the corresponding decrease in the HVL of the studied glasses can be attributed to the gradual replacement of $\mathrm{RH}$ silica by $\mathrm{Bi}_{2} \mathrm{O}_{3}$. This can be understood logically by knowing that the $\gamma$-ray mass attenuation coefficient of bismuth is higher than that of silicon, while the HVL of bismuth is smaller than that of silicon. The $\mu / \rho\left(\mathrm{cm}^{2} / \mathrm{g}\right)$ for bismuth and silicon as well as for oxygen and sodium are exhibited in Table 2 for comparison [36].

Table 2. $(\mu / \rho)_{m}\left(\mathrm{~cm}^{2} / \mathrm{g}\right)$ and $H V L(\mathrm{~cm})$ for bismuth and silicon at different low $\gamma$-ray energies [36].

\begin{tabular}{lllll}
\hline & & $(\boldsymbol{\mu} / \mathbf{\rho})_{\mathbf{m}}$ & $\left(\mathbf{c m}^{2} / \mathbf{g m}\right)$ & \\
\hline Energy $(\mathrm{KeV})$ & $356 \mathrm{Kev}$ & $662 \mathrm{Kev}$ & $1173 \mathrm{Kev}$ & $1332 \mathrm{Kev}$ \\
$\mathrm{Bi}$ & 0.2960 & 0.1130 & 0.0626 & 0.0569 \\
$\mathrm{O}$ & 0.1000 & 0.0773 & 0.0588 & 0.0551 \\
$\mathrm{Si}$ & 0.1010 & 0.0773 & 0.0588 & 0.0551 \\
$\mathrm{Na}$ & 0.0963 & 0.0740 & 0.0563 & 0.0528 \\
\hline
\end{tabular}

Generally, it can be stated that, all the studied glasses can be used as gamma-ray shield and to capsulate nuclear radio-active wastes before interment underground. These samples work well for law than for high gamma-ray energies. It is worth to state also that the sample containing $20 \mathrm{~mol} \%$ $\mathrm{Bi}_{2} \mathrm{O}_{3}$ appeared to be of high suitability to act as shield for the $356 \mathrm{keV}$ gamma-ray energy, since it presents the highest $\mu / \rho$ coefficient and lowest HVL values.

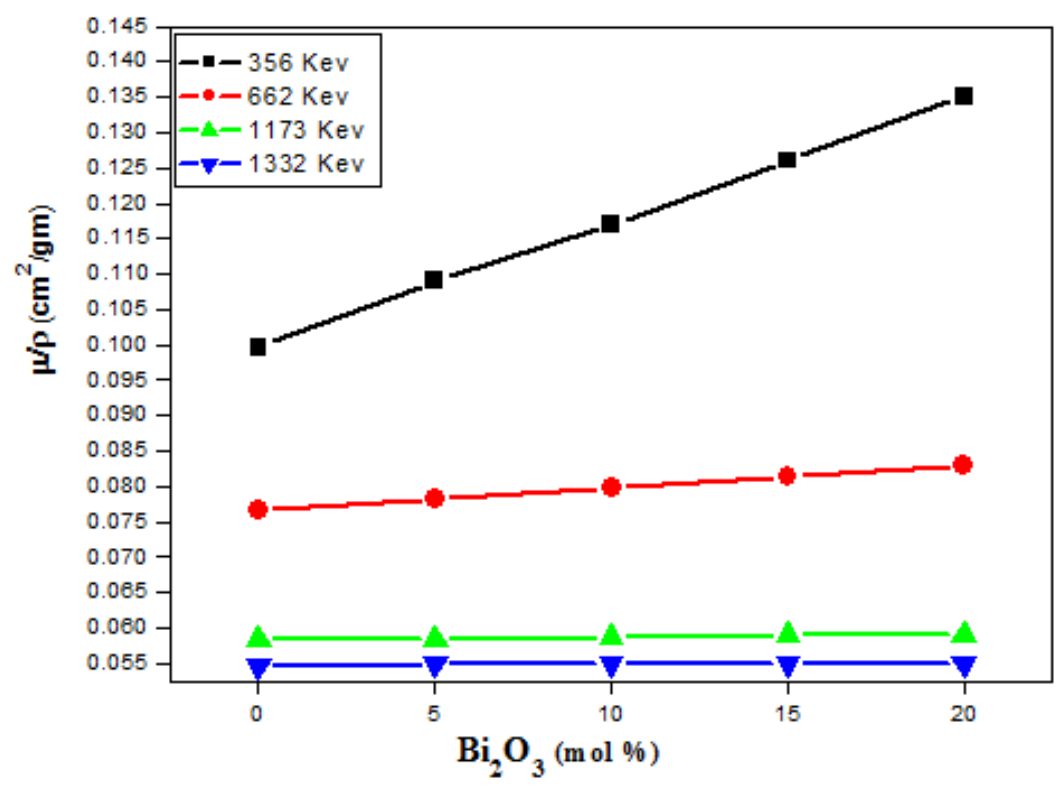

Fig. 4. The mass attenuation coefficient versus $\mathrm{Bi}_{2} \mathrm{O}_{3}$ content for different low $\gamma$-ray energies.

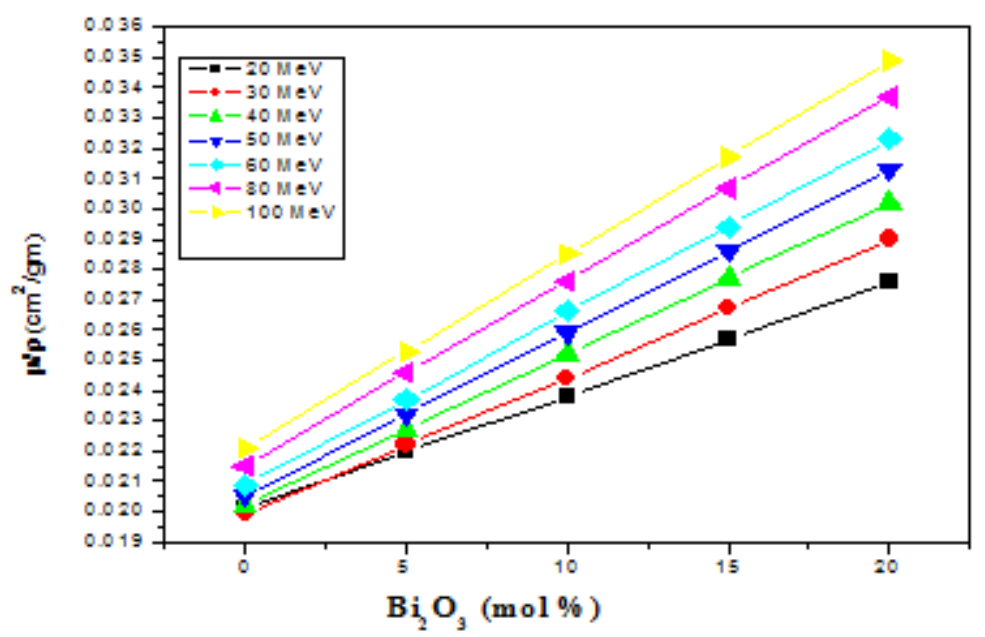

Fig. 5. The mass attenuation coefficient versus $\mathrm{Bi}_{2} \mathrm{O}_{3}$ content for different high $\gamma$-ray energies. 


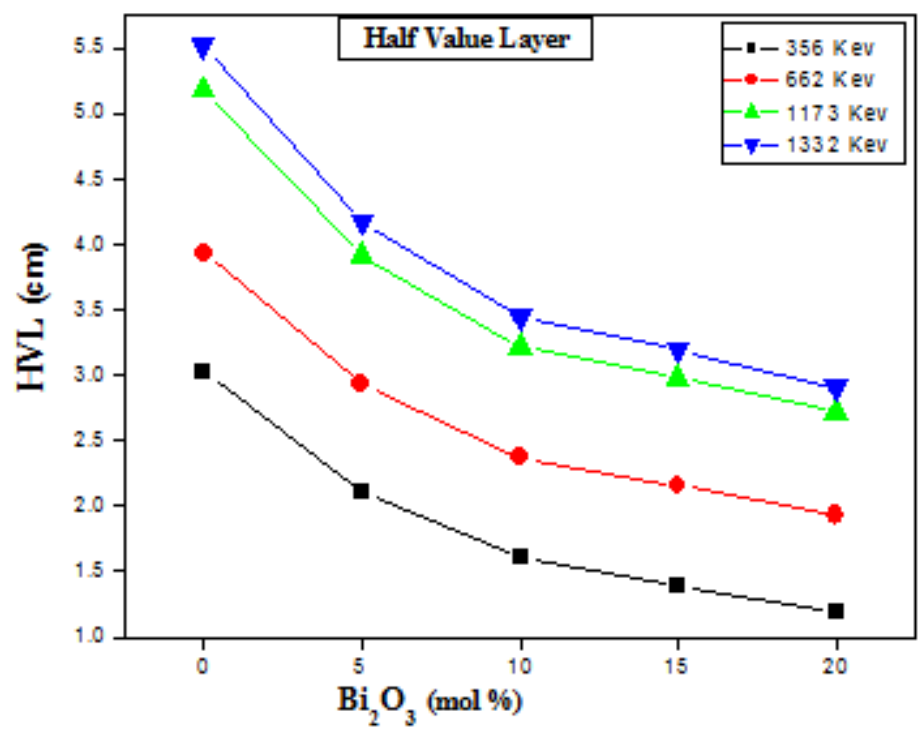

Fig. 6. The HVL of the investigated glasses versus $\mathrm{Bi}_{2} \mathrm{O}_{3}$ content for different low $\gamma$-ray energies.

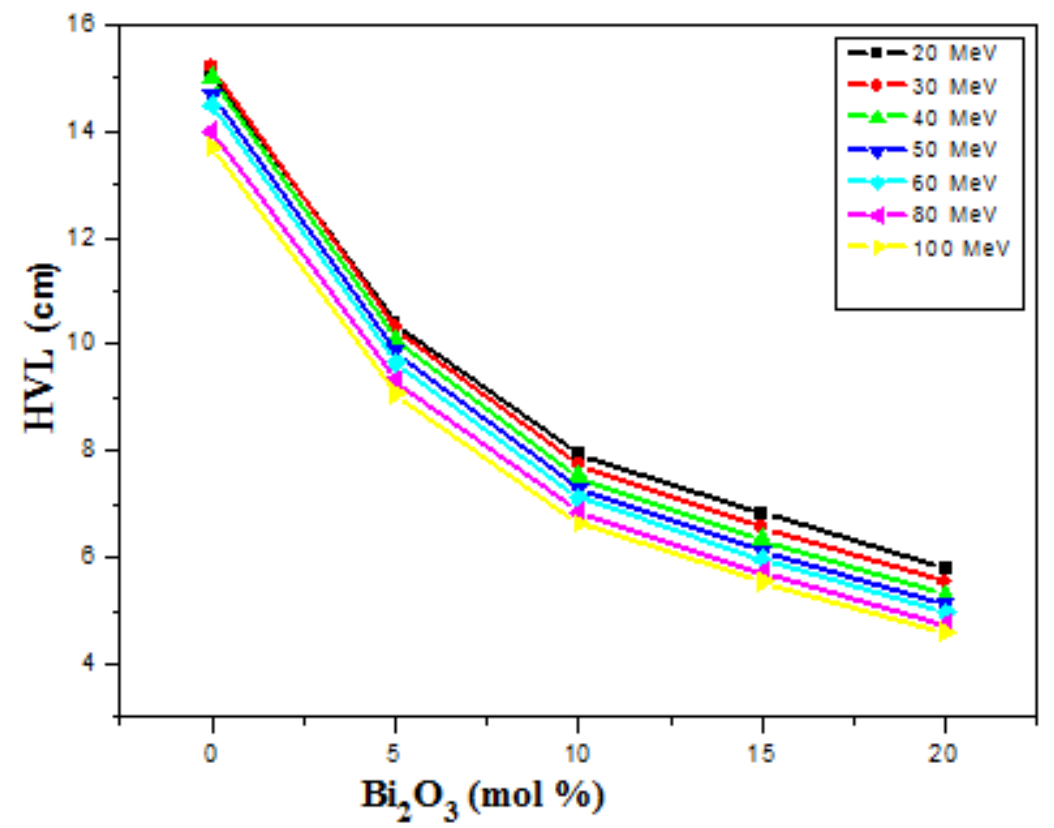

Fig. 7. The HVL of the investigated glasses versus $\mathrm{Bi}_{2} \mathrm{O}_{3}$ content for different high $\gamma$-ray energies.

\subsubsection{Total Mass Attenuation Coefficients as a Function of Incident Gamma Ray Energies [37-39]}

The mass attenuation coefficient $(\mu / \rho)_{m}$ for the studied glass samples, has been presented graphically in Fig. 8 as a function of the incident gamma-ray energy. It is clear that, at low incident photon energies $(0.001-0.20 \mathrm{MeV}),(\mu / \rho)_{\mathrm{m}}$ decreases rapidly from $3.24 \times 10^{3}$ at $0.001 \mathrm{MeV}$ to $4.87 \times 10^{-1}$ at 0.20 $\mathrm{MeV}$. When the incident photons energy increased at the intermediate energy range $(0.20 \mathrm{MeV}-20 \mathrm{MeV})$, it decreases slowly. Finally, at high energy regions $(\mathrm{E}>20 \mathrm{MeV})$, it appeared to be approximately stable. This behavior can be explained by the fact that the dominance of different interaction processes of photon with matter (photoelectric absorption, Compton scattering and pair production in nuclear field and in electronic field) is not the same for different photon energies.

Fig. 9 shows the partial mass attenuation coefficients of different photon interaction processes for the studied glass system. It is clear that at low energy region, the photoelectric absorption is the dominant process and the contribution of other processes is negligible. Also, it can be noted that the partial mass attenuation coefficients of the photoelectric absorption decreases rapidly and its contribution becomes negligible starting from $0.20 \mathrm{MeV}$, because its effective cross section is inversely proportional to the incident photon energy [40]. Therefore, the fast decrease of the total mass attenuation coefficient at low energy range is caused by this effect.

It can be noted also that when the incident photon energy is between 0.20 and $20 \mathrm{MeV}$, Compton scattering process (especially incoherent) becomes the dominant mechanism, and its partial mass attenuation coefficients increases when the 
energy is between 1 and $20 \mathrm{keV}$. But it is smaller than the partial mass attenuation coefficients of the photoelectric absorption. Then, it becomes almost constant up to $150 \mathrm{keV}$ and from this value it decreases slowly. The behavior of this coefficient is due to the fact that the cross section of Compton scattering process is inversely proportional to the incident photons energy [41]. Therefore, the slow decrease in $(\mu / \rho)_{m}$ values in the intermediate energy can be explained by the dominance of the Compton scattering process. Finally, in the high energy region, the pair-production process becomes dominant. The partial mass attenuation coefficient of this process is zero for an energy between $1 \mathrm{keV}$ and $1.02 \mathrm{MeV}$. Then, it increases linearly with the increase of energy and when the energy is $24 \mathrm{MeV}$ it becomes equivalent to the partial mass attenuation coefficients of the Compton scattering process and from $100 \mathrm{MeV}$ it becomes almost constant. So, this may explain why $(\mu / \rho)_{\mathrm{m}}$ remains almost constant in the high photon energy region.

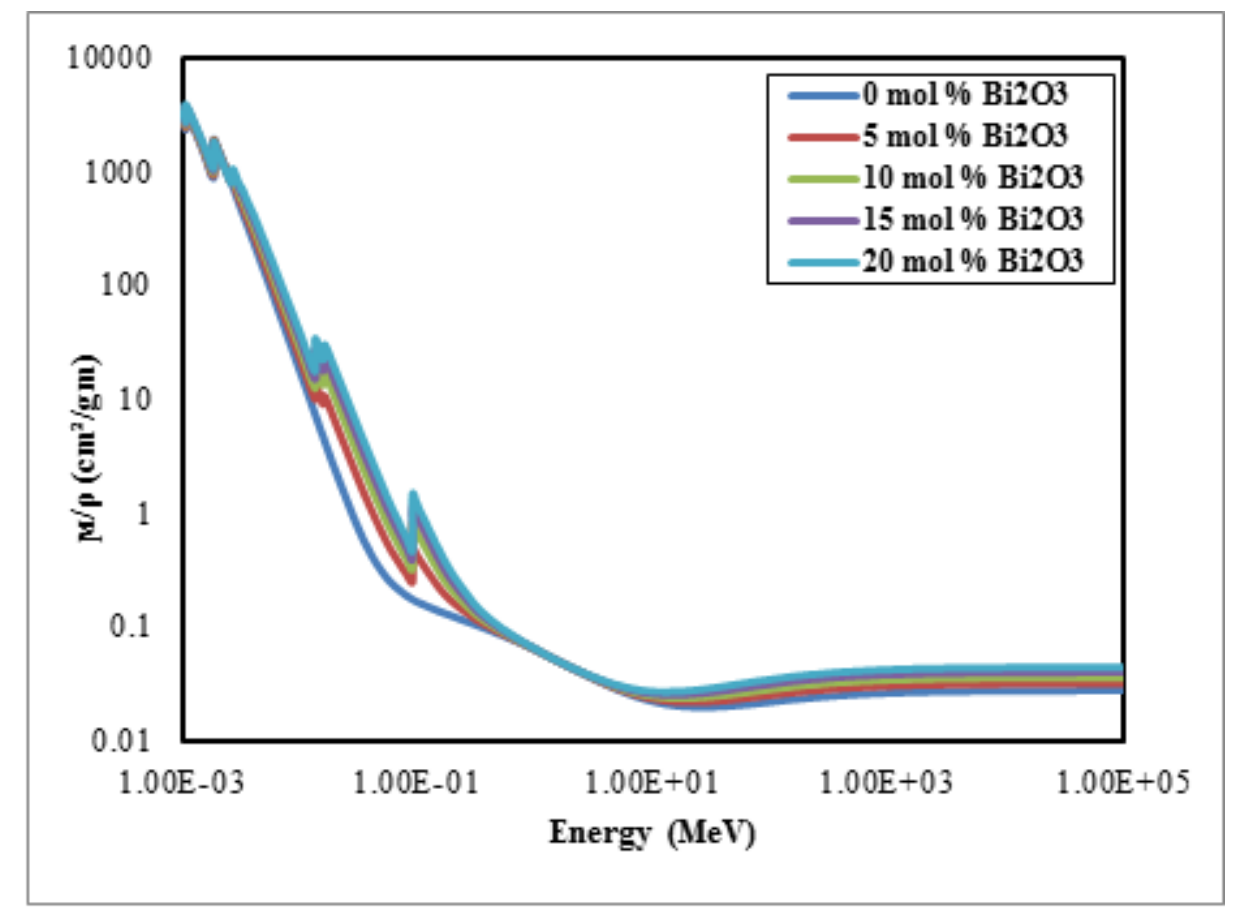

Fig. 8. The mass attenuation coefficient for the studied glasses as afunction of the incident gamma ray energies.

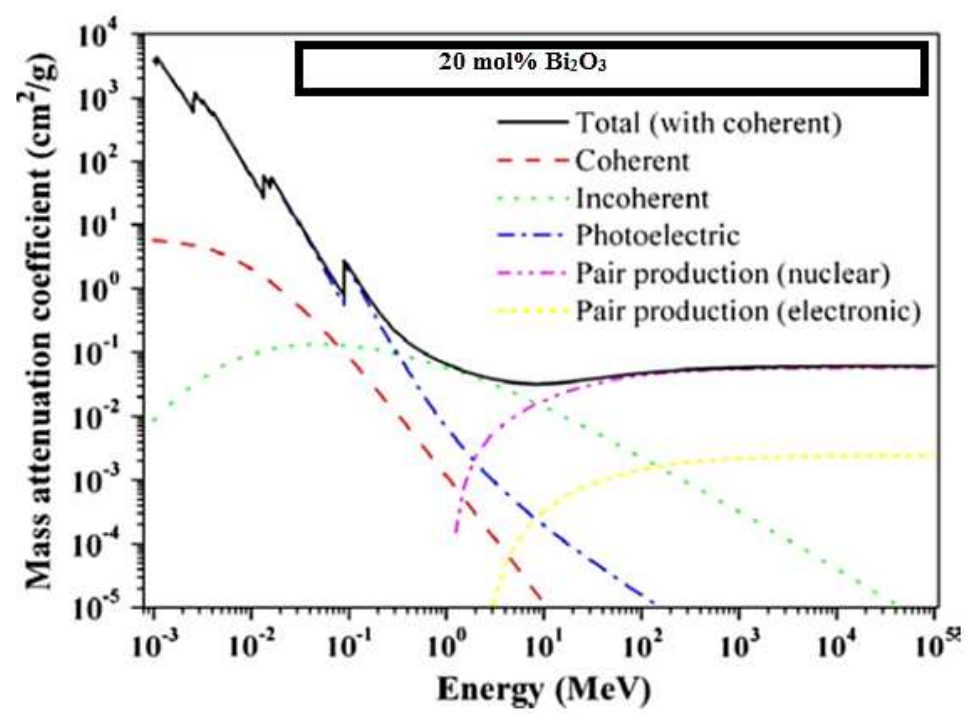

Fig. 9. The variation of mass attenuation coefficient for $20 \mathrm{~mol} \% \mathrm{Bi}_{2} \mathrm{O}_{3}$ glass sample with photon energy for total and partial interactions (with coherent).

\subsection{Fast Neutron Removal Cross Section}

Fast neutron attenuation is described by a parameter called the "removal cross-section", denoted by $\Sigma \mathrm{R}\left(\mathrm{cm}^{-1}\right)$. It is different from the total macroscopic cross-section but it has only a fraction of the macroscopic cross section. The removal cross- section presents the probability that a fast or fission-energetic neutron undergoes a first collision, which 
removes it from the group of penetrating un-collided neutrons [41-43]. Indeed, in the MeV-energy region, the absorption cross-section of neutrons is very low compared to the scattering cross-section. In fact, the fast neutrons are not directly absorbed during their passage through the shielding hydrogenated, but they slow primarily by successive elastic collisions with the nuclei of light elements and when their energy is in the order of the thermal energy $(0.025 \mathrm{eV})$, they are absorbed by the nuclei of heavy elements via interaction radiative capture [43].

Generally, shielding materials are chemical compounds or mixtures, their macroscopic removal cross-section can be obtained by calculating their $(\Sigma \mathrm{R})_{\mathrm{C}}$ of their constituent elements applying the following equation, [41-43],

$$
(\Sigma R) c=\sum_{\mathrm{i}} \mathrm{W}_{\mathrm{i}}\left(\sum \mathrm{R} / \rho\right) i
$$

Where $\mathrm{W}_{\mathrm{i}}, \rho$ and $\left(\sum \mathrm{R} / \rho\right) i$ are respectively the partial density $\left(\mathrm{g} \mathrm{cm}^{-3}\right)$, density and mass removal cross section of the ith constituent [44]. Fig. (10) Shows the mass removal cross-sections $(\Sigma \mathrm{R})_{\mathrm{C}}$ as a function of $\mathrm{Bi}_{2} \mathrm{O}_{3}$ concentration. The calculated values of removal cross-sections $(\Sigma \mathrm{R})_{\mathrm{C}}$ show that the sample contained $5 \% \mathrm{Bi}_{2} \mathrm{O}_{3}$ has the largest removal cross-section and the sample no. $1,\left(\mathrm{Bi}_{2} \mathrm{O}_{3}\right.$ free sample) has lowest one as shown in Fig. (10). Therefore, the addition little of $\mathrm{Bi}_{2} \mathrm{O}_{3}$ improves the removal cross section values of these glasses.

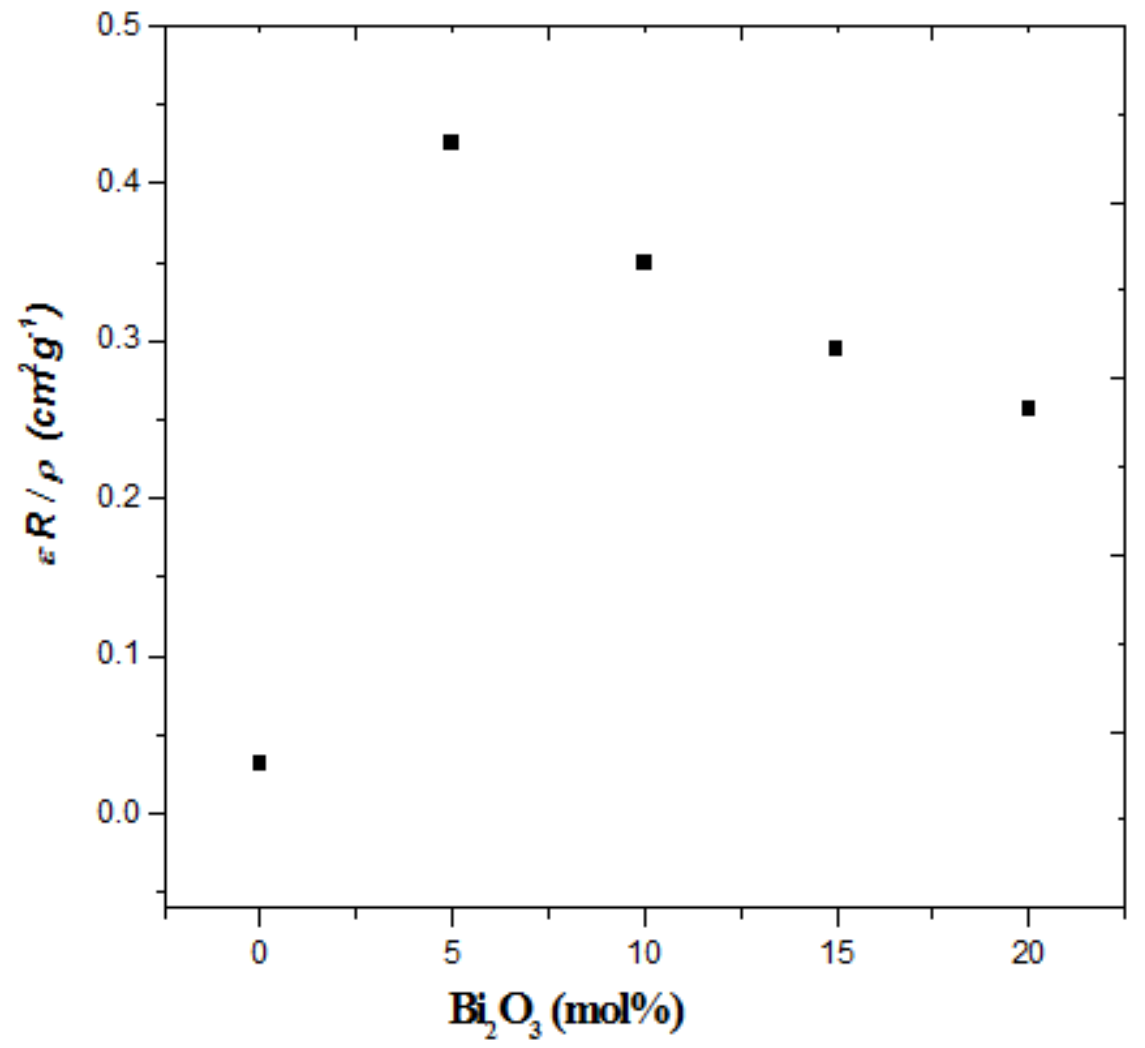

Fig. 10. The removal cross-section $(\Sigma R)_{C}$ of fast neutron's for the studied glass system.

\section{Conclusions}

- High pure Silica content can be extracted from RH after chemical and thermal treatments, and homogenous transparent glasses can be manufactured using such $\mathrm{RH}$ silica for various scientific and industrial applications.

- The introduction of $\mathrm{Bi}_{2} \mathrm{O}_{3}$ in elevated amounts increases gradually the density and the molar volume of the studied samples.

- According to the shielding properties, gamma-ray shielding glass can be prepared from $\mathrm{RH}$ silica as host glass doped with bismuth oxide. It is seen that, as $\mathrm{Bi}_{2} \mathrm{O}_{3}$ was increased the gamma-ray mass attenuation coefficient increased and consequently the HVL decreased. Among all glasses the sample that contains 20 $\mathrm{mol} \% \mathrm{Bi}_{2} \mathrm{O}_{3}$ is the best one for attenuate $356 \mathrm{keV}$ gamma ray energy, it seen also that, the sample that contains 5 mol\% $\mathrm{Bi}_{2} \mathrm{O}_{3}$ is the efficient one for attenuate neutrons since it show the highest $(\Sigma \mathrm{R})_{\mathrm{c}}$, in comparison to all other glasses.

\section{References}

[1] M. Jalali and A. Mohammadi, J. Radiat. Phys. Chem., 77 (2008) 523.

[2] N. Chanthima, J. Kaewkhao and P. Limsuwan, J. Ann. Nucl. Energy, 41 (2012) 119.

[3] N. Chanthima, P. Prongsamrong, J. Kaewkhao and P. Limsuwan, J. Procedia Eng., 32 (2012) 976.

[4] J. Kaewkhao and P. Limsuwan, J. Nucl. Instrum. Method Phys. Res. A, 619 (2010) 295. 
[5] K. Kirdsiri, J. Kaewkhao, N. Chanthima and P. Limsuwan, J. Ann. Nucl. Energy, 38 (2011) 1438.

[6] M. Kurudirek, Y. Ozdemir, O. Simsek and R. Durak, J. Nucl. Mater., 407 (2010) 110.

[7] S.R. Manohara, S.M. Hanagodimath and L. Gerward, J. Nucl. Mater., 393 (2009) 465.

[8] H. Singh, K. Singh, L. Gerward, K. Singh, H.S. Sahota and R. Nathuram, J. Nucl. Instrum. Method Phys. Res. B, 207 (2003) 257.

[9] K. Singh, H. Singh, V. Sharma, R. Nathuram, A. Khanna, R. Kumar, S.S. Bhatti and H.S. Sahota, J. Nucl. Instrum. Method Phys. Res. B, 194 (2002) 1.

[10] K. Singh, H. Singh, G. Sharma, L. Gerward, A. Khanna, R. Kumar, R. Nathuram and H.S. Singh, J. Radiat. Phys. Chem., $72(2005) 225$.

[11] K.J. Singh, N. Singh, R.S. Kuandal and K. Singh, J. Nucl. Instrum. Methods. B, 266 (6) (2008) 944.

[12] S. Singh, A. Kumar, D. Singh, K. Singh, K.S. Thind and G.S. Mudahar, J. Nucl. Instrum. Meth. B, 266 (1) (2008) 140.

[13] N. Singh, K.J. Singh, K. Singh and H. Singh, J. Nucl. Instrum. Method Phys. Res. B, 225 (2004) 305.

[14] N. Singh, K.J. Singh, K. Singh and H. Singh, J. Radiat. Meas., 41 (2006) 84.

[15] L. Gerward, N. Guilbert, K.B. Jensen and H. Levring, J. Radiat. Phys. Chem., 60 (2001) 23.

[16] L. Gerward, N. Guilbert, K.B. Jensen and H. Levring, J. Radiat. Phys. Chem., 71 (2004) 653.

[17] Japan Cement Association, 2008. Report: Cement Demand and Supply in Japan, 1.

[18] S. Chandrasekhar, PN. Pramada and J. Majeed, J. Materials Science, 41 (2006) 7926.

[19] S. Chandrasekhar, PN. Pramada and L. Praveen, J. Materials Science, 40 (2005) 6535.

[20] H. A. Saudi, S. M. Salem, S. S. Mohammad, A. G. Mostafa and M. Y. Hassaan, to be published in the American Journal of physics and applications, (2015).

[21] A.K. Varshneya, "Fundamentals of Inorganic Glasses," Society of Glass Technology, Sheffield, UK, 2006.

[22] N. Singh, K. J. Singh, K. Singh and H. Singh, J. Nucl. Instr. Meth. (B), 225 (2004) 305.

[23] N. Singh, K. J. Singh, K. Singh and H. Singh, J. Radiat. Meas., $41(2006) 84$.
[24] K. J. Singh, N. Singh, R. S. Kaundal and K. Singh, J. Nucl. Instr. Meth. (B), 266 (2008) 944.

[25] N. Singh, R. Singh and K. J. Singh, Glass Technol., 46 (4) (2005) 311 .

[26] M. E. Medhat, J. Ann. Nucl. Energy, 36 (2009) 849.

[27] U. Cevik, N. Damla, A. I. Kobya, N. Celik, A. Celik and A. A. Van, J. Radiol. Prot., 29 (2009) 61.

[28] A. G. Mostafa, M. Y. Hassaan, A. A. Ramadan, A. Z. Hussein and A. Y. Abdel-Hassib, J. Nature and Science, 11 (5) (2014) 148 .

[29] J.E. Shelby, the Royal Society of Chemistry, UK, (1997) 137.

[30] H. A. Saudy, S. El Mosallamy, S. U. El Kameesy, N. Sheta, A. G. Mostafa, and H. A. Sallam, World J. Condens. Matter Phys., 03 (2013) 9.

[31] R. El-Mallawany, N. El-Khoshkhany and H. Afifi, J. Materials Chemistry and Physics, 95 (2006) 321.

[32] C. Narayana Reddy, V. C. Veeranna Gowda and R. P. Sreekanth Chakradhar, Journal of Non- Crystalline Solids, 354 (2008) 32.

[33] Yasser B. Saddeek, M. S. Gaafar and Safaa A. Bashier, J. Journal of Non-Crystalline Solids, 356 (2010) 1089.

[34] J. Qi, D. Xue, H. Ratajczak and G. Ning, Physica B, 349 (2004) 265.

[35] H. Doweidar and Yasser B. Saddeek, J. Non-Crystalline Solids, 355 (2009) 348.

[36] S. S. Mohammad, M. Sc. Thesis, Al-Azhar Univ., (2012).

[37] D. A. Magdas, A, Cosar, V. Chis, I. Ardelean and N. Vedeanu, Vib. Spectrosc., 48 (2008) 251.

[38] L. Gerward, N. Guilbert, K.B. Jensen and H. Levring, J. Radiat. Phys.Chem., 71 (2004) 653.

[39] J. H. Hubbell, Int. J. Appl. Radiat. Isot., 33 (1982) 1269.

[40] J. H. Hubbell, J. Phys .Med. Biol., 44 (1999) 1.

[41] I. I. Bashter, J. Ann. Nucl. Energy, 24 (1997) 1389.

[42] A. B. Chilton, J. K. Shultis and R. E. Faw, principles of Radiation Shielding, Prentice Hall, New York., (1984)

[43] M.F. Kaplan, Wiley, New York (1989).

[44] H. A. Saudi, J. Applied Mathematics and Physics, 4 (2013) 143. 